\title{
Advocating for Your Department through a School Merger: The Chair Perspective
}

\section{Mark Urtel}

Amanda K. Cecil

As department chairs, much of what we do has an element of advocacy to it. Depending on the situation presented to us, we routinely advocate for the integrity of the curriculum, department policy and procedure, faculty voice, or student success, among many other examples. Moreover, acknowledging that in most cases we are leading from the middle, the goal of our advocacy efforts is to find a win-win position, where the affected stakeholders all feel they were heard and dealt with fairly. Although this type of advocacy occurs in many forms, from typical semester, monthly, weekly, or daily interactions, it differs greatly from advocacy that is done during significant change. This article will highlight one such example: representing the department's best interests during a school merger. In this instance, the chairs' advocacy efforts are not typical, nor were they particularly driven by a win-win ethos. In our experience, the advocacy efforts we used during a combining of schools were far greater and more involved than those found within the daily job of a chair.

Clearly, academic restructuring is not a new practice in higher education (Gumport 2000). The common factor, as Feldman and Benz (2005) point out, is that there is a re-engineering of administrative and financial infrastructure. In fact, an equivalent to consider a restructuring in higher education is with a corporate restructuring (Burris 2008; Gumport 2000). As a result, what made our advocacy efforts unique and challenging is that this possible merger arose out of

This is the authors' manuscript of the work published in final form as:

Urtel, M., \& Cecil, A. K. (2019). Advocating for Your Department through a School Merger: The Chair Perspective. The Department Chair, 30(2), 3-5. https://doi.org/10.1002/dch.30279 
convenience, not administrative or financial need. This is almost unheard of in higher education today.

In our case, the identified schools were financially strong and thus had no reason to merge, much less to change. Key metrics, including budget reserves, enrollment, time to graduation, and alumni satisfaction, confirmed our respective success. Ironically, this adds an interesting dimension to our advocacy, as a main question from faculty and staff centered on "Why merge?"

For context, campus administrators had asked us previously to explore a school merger. Those proposals were rejected. Yet early in 2017, campus administrators approached us again for a restructuring conversation. Unlike prior occasions, we learned that another school on campus requested the conversation. Apparently, their recently failed dean's search prompted the inquiry; ironically, we also had an interim dean. From the campus administration perspective, the timing for another conversation about restructuring/merging was ideal, and we could not strongly argue against that assertion. We reasoned that it might be better to engage in a conversation where we might be able to control the dialogue, from a position of strength instead of this happening to us; instead, it would happen with us. Consequently, we agreed to explore and discuss the possibility of combining efforts. After a formal review that lasted about three months, we agreed to come together as one unit.

It is important to know that our prior school had a clear undergraduate focus, and our prospective partner school had a clear professional school/graduate degree focus. From the thirty-thousandfoot view, this conversation makes sense, as we will not be competing for students. Rather, this seems like a natural fit for comprehensive academic programming. However, as the view approaches ground level, it quickly became clear that there were significant architectural 
differences between us. What was revealed to us as chairs during the long process of restructuring warranted novel and intentional advocacy efforts.

Anyone who has been involved in academic mingling can attest that there are many competing interests at stake. This article will highlight the areas that directly affected us at the chair level and that demanded much of our attention and energy. We will address department structure, chair duties, and program fit as the main points of our advocacy. Furthermore, we will identify how advocacy evolved into enduring work or episodes of influence.

\section{Department Structure}

Our focus as chairs in advocating for structure was twofold. First, we wanted to ensure that everything that was externally facing during the restructuring process would be preserved. An example was student success—-from student recruitment/admissions through to graduation. Second, our newfound structure would be fair, equitable, and universal.

In our preceding school configuration, department staff did not exist. All staff reported to the dean's office, whether that was budget, administrative, student success, marketing, development, and the like. For our upcoming partners, they had staff dedicated to specific departments, to include administrative and advising-based professionals.

The questions became: How will this affect workflow, and which model will be the universal model of the school? Initially we were excited at the notion of having department-level staff, for several reasons. We quickly realized, however, that changes would not be easy. As a result, there were many discussions about the benefits and limitations of each model, and we actively advocated for a universal support system—-but unsuccessfully so thus far. Yet with continued 
meetings, emails, and discussions, this necessary enduring advocacy underscores our reality of building the ship as we sail it.

\section{Chair Duties}

Department chair responsibilities are, paradoxically, consistent yet ever changing. More importantly, they are time sensitive. What's more, when one holistically looks at the curriculum, the faculty, or the budget, size matters. The number of faculty, students, facilities, and curricular experiences that are within a department greatly influence the overall scope and scale of the work. For example, each of the following tasks vary greatly depending on the size of your department:

- Building course schedules

- Auditing graduation applications and course adjustments

- Monitoring budgetary items, approving and/or denying faculty requests

- $\quad$ Scheduling meetings

- Communicating with part-time faculty

- Hearing student appeals

- $\quad$ Meeting with prospective students

- Addressing stakeholders both within and external to the campus

- Quickly addressing the daily "urgent" issues that arise

Therefore, your ability to advocate for yourself to ensure that you have the time, not to mention the internal support staff, to accomplish these tasks is vital for your sustained service. This is 
another example of enduring advocacy. Although we spoke early and often for common department structures to support the already good work that has been going on, there are still adjustments being made well after the official restructuring, and we anticipate this to be the case well into the future.

Curriculum. What emerged quickly in our restructuring discussions is how different each department curriculum was and how that influenced chair duties and workload. In our prior school, we as chairs relied heavily on enrollment from our major program classes, general education coursework, and elective coursework. Within the responsibility-centered management budget model we operate within, our focus was always on offering high-impact practices to our enrolled students in the most engaging and productive manner possible. Most of our chair analogs from the partnering school offered scripted curriculums in an annual cohort manner with little deviation semester to semester.

As a result, they were not oriented as much nor as mindful of the inclusive undergraduate student experience. As a result, we had to advocate for how important and significant the responsibility for course scheduling is on a semester basis. The most powerful advocacy tool in accomplishing this is data, plain and simple. When it is revealed that more than 55 percent of a school's budget comes from the credit hours generated from one of the eight departments, that gets attention. The significant reminder about course enrollment, via words or visual display, is a form of episodic advocacy—when peers or administrators see the effect of enrollment, it is better understood.

Faculty. Although there are many tasks that increase with more faculty, the most relatable is the annual faculty review and evaluation process. As chair of a department with twenty-three faculty, my advocacy efforts are markedly different from my colleague's, who may have five faculty members. Let us state that we also appreciate that there are many chairs with faculty 
numbering in the forties and fifties and even much greater. We certainly understand that faculty size is relative.

Yet for our case, advocacy was necessary, and it was important to remind our new colleagues that there is a larger time demand necessary to review the annual reports of twenty-three faculty than there is of five faculty. Going into the first cycle of these annual reviews, postmerger, the originally proposed timetable was to complete faculty reviews and meetings two to three weeks after the annual reports were due. I then started with my advocacy efforts and reiterated that I may not even be able to read each evaluation in that timeframe much less have any of the followup meetings scheduled. I also highlighted that there are subsequent downstream effects with a larger faculty and they continue when you add the time needed for face-to-face meetings with twenty-three faculty as opposed to five faculty.

Finally, it takes more time to coordinate, schedule, and host meetings for twenty-three faculty than it would for five faculty. To make a connection to the department architecture issue noted earlier, ironically, as chair of a department with the largest faculty, I did not have direct staff support. This means I led the work to, literally, do the scheduling for these meetings. Unlike the chairs of the partnering school, I was not able to use department staff for these significant yet clerical tasks. As a result, be prepared to advocate for yourself unapologetically and without hesitation when it comes to the time necessary to complete tasks with a larger faculty.

\section{Program Fit}

As the former chair within our original school, my observation was that I was leading a department that can strongly be considered an "outlier" for this new school. Six of the eight departments could find synergies under health-related research projects, courses, and initiatives. 
However, our event and sport management focus needed to clearly articulate its value in the restructure and show that it could be innovative in collaborating with colleagues in all departments. At times our new colleagues misunderstood our faculty's focus, and with due diligence, I had to reassure my department faculty of their value throughout the process. This requires a sense of patience, and, as we have alluded to before, this is a form of enduring advocacy.

\section{Conclusion}

When faced with a school merger for reasons beyond financial despair, chairs must recalibrate their advocacy efforts from the intuitive mind-set of win-win to a department-centric mind-set. Moreover, their work should include both influential episodes of advocacy and enduring efforts. With regard to the episodes of advocacy, use compelling evidence to underscore your position. For enduring advocacy efforts, the key is to be persistent with your narrative and to not get discouraged. Listen, learn, and keep at it. We summarize, unapologetically so, that if chairs do not advocate for their departments, who will?

This article is based on a presentation at the 36th annual Academic Chairpersons Conference, February 6-8, 2019, Houston, Texas.

\section{About the Authors}

Mark Urtel is associate professor and chair of the Department of Kinesiology and Amanda K. Cecil is associate professor and chair of the Department of Tourism, Conventions, and Event Management at Indiana University-Purdue University Indianapolis. Email: murtel1@iupui.edu, akcecil@iupui.edu 


\section{References}

Burris, B. H. 2008, July. "Restructuring the Academic Workplace: Corporatization

Reconsidered." Paper presented at the Annual Meeting of the American Sociological Association, Boston, MA.

Feldman, Arthur M., and Edward J. Benz Jr. 2005. "Restructuring the Academic Department of Internal Medicine.” American Journal of Medicine 118 (12): 1430-35.

Gumport, Patricia J. 2000. “Academic Restructuring: Organizational Change and Institutional Imperatives.” Higher Education 39 (1): 67-91. 